\title{
Kış Turizmi Çalışmaları Üzerine Bibliyometrik Bir İnceleme
}

\section{A Bibliometric Study on Winter Tourism Studies}

\author{
Arş. Gör. Burcu KARASAKALOĞLU \\ Alanya Alaaddin Keykubat Üniversitesi \\ Turizm Fakültesi, Antalya, Türkiye \\ E-posta: burcu.karasakaloglu@alanya.edu.tr
}

\section{Öz}

Bu çalışmada, kış turizmi konusunu ele alan çalışmalar bibliyometrik analiz yöntemi ile incelenerek ilgili literatürün mevcut durumunun ortaya konması amaçlanmıştır. Çalışmada, Web of Science (WOS) veri tabanında yer alan kış turizmi konulu 218 makaleye ulaşılmıştır. Veriler, Citespace II analiz programı ile bibliyometrik analize tabi tutulmuştur. Kış turizmi çalışmaları; atıf ağı, dergi ve ülke iş birliktelikleri ile anahtar kelimeleri ağı parametreleri çerçevesinde analiz edilmiştir. Araştırma sonucuna göre, en fazla ortak atıf alan yazar Scott, D. olurken en fazla atıf patlamasına sahip yazar Pickering, C. olmuş ve Tourism Management dergisi de ağda merkezi bir konumda yer almıştır. En çok atıf alan yayınların ise kış turizmi ve iklim değişikliğini inceleyen çalışmalar olduğu, önemli kayak merkezlerinin bulunduğu Avusturya ve İsviçre'nin de en çok ülke iş birlikteliği yapan ülkeler olduğu anlaşılmıştır.

Anahtar Kelimeler: Turizm, Kış turizmi, Bibliyometrik analiz.

\begin{abstract}
In this study, it is aimed to examine the current state of the related literature by examining the studies in the field of winter tourism with bibliometric analysis method. In the study, 218 winter tourism studies were reached in the Web of Science (WOS) database. The data were analyzed via the Citespace II bibliometric analysis program. The data were analyzed within the framework of citation information, journal, country collaborations and keywords parameters.According to the results of the research, it was determined that the author who received the most common citation was Scott, D., the writer with the highest citation burst was Pickering, $\mathrm{C}$. and the journal which was in a central position in the network was Journal of Tourism Management. Besides, It was understood that the most cited publications were studies examining winter tourism and climate change. In addition, it has been understood that Austria and Switzerland, where there are important ski resorts, are the countries that cooperate with the most countries.
\end{abstract}

Key Words: Tourism, Winter tourism, Bibliometric analysis. 


\section{Giriş}

Günümüzde bireyler, günlük iş rutinlerinden zaman zaman uzaklaşmak, yeni yerler görmek ve yeni insanlar ile tanışmak istemektedir (Ryan, 2002). Dünyada meydana gelen teknolojik gelişmeler ve sosyolojik değişimler sonucunda ise turizm endüstrisinde farklı talepler oluşmakta ve dolayısıyla farklı turizm türleri ilgi görmektedir (Yılmaz ve Gürol, 2012). Insanların farklı tatil deneyimi arayışları, kitle turizminin yanında alternatif turizm türlerinin de ön plana çıkmasına yol açmıştır (Kılıç ve Kurnaz, 2010). Bir başka ifade ile kitle turizminin yapısından memnun olmayan kişiler, ekonomik, sosyal ve kültürel sonuçları ile farklı bir deneyim sunan alternatif turizme yönelmişlerdir (Cohen, 1987). Kış turizmi, karlı ve dağlık alanlardaki konaklama hizmetlerini içeren bir turizm türü olmasının yanında kış sporlarına dayalı bir turizm türüdür (Oktayer ve diğ., 2007). Günümüzde seyahat etme imkanının kolaylaşması ile birlikte, kış mevsiminde karlı bölgelerde konaklama ve eğlence gibi hizmetlerin sunulması kış turizmine katılmak isteyen turistlerin hareketliliğini desteklemekte ve seyahatleri artırmaktadır (Unbehaun ve diğ., 2008). Sadece Avrupa Birliği ülkeleri içerisinde 2018-2019 kış sezonunda kendi ülkelerinin dışında seyahat eden turistler için en popüler yerler İspanya, İngiltere, İtalya ve Avusturya olmuştur. Bu dört ülkenin kış turizmi gecelemeleri, yerleşik olmayanlar tarafından gerçekleştirilen ve Avrupa Birliği'nde bulunan otellerin bütün gecelemelerinin yarısından fazlasını (\%55) oluşturmaktadır (Eurostat, 2019). Türkiye'de ise 2018 yılında gelen 39 milyon yabancı turistin sadece \%1'i kış turizmi için gelmiştir. Kış turizmi için ülkemize gelen yabancı turist sayısı geçmiş yıllara göre belirli bir oranda artmış olsa da yıllar içerisinde düzenli bir artış gerçekleşmemiştir (Demir, 2019). Dolayısıyla, ülkemizde kış turizminin gelişebilmesi ve bilimsel çalışmaların yapılabilmesi için dünyadaki kış turizmi ile ilgili bilimsel çalışmaların mevcut durumunun incelenmesinin ve tartışılmasının önem arz ettiği düşünülmektedir.

$\mathrm{Bu}$ bağlamda çalışmada kış turizmi ile ilgili çalışmaların bibliyometrik analiz yöntemi ile incelenmesi amaçlanmıştır. Ayrıca, kış turizmi ile ilgili güncel konular, alanda ön plana çıkan çalışmalar, yazarlar, dergiler, ülkeler ve anahtar kelimeler incelenerek kış turizmi alanındaki çalışmalar hakkında bilgi verilmiştir. Bibliyometrik analizin temel amacı ise kütüphane koleksiyonlarını bilgi, iletişim ve bilimsel açıdan nicel analiz yöntemi ile değerlendirmektir. Bibliyometrik çalışmalar, bilimsel araştırmaların yazar, yayın ve atıf kaynakları gibi farklı parametrelerce istatistiki yöntemler ile incelenmesini ve bir disipline ya da alana ait genel durumunun ortaya konmasını sağlamaktadır (Zan, 2012: 15). Bibliyometrik analiz, bilimsel araştırmanın daha iyi anlaşılmasına katkıda bulunmakla birlikte, bilimsel bilgilendirme yönünün de oluşmasını, yayıımasını ve kullanılmasını sağlamaktadır (Osareh, 1996). Bu bağlamda, kış turizmi konulu araştırmalar, farklı parametreler açısından bibliyometrik analiz ile incelenerek söz konusu araştırmaların genel eğilimleri hakkında bir perspektif sunulmuştur. Dolayısıyla, kış turizminin bilimsel alanda gelişimi hakkında bilgi sahibi olmak için kış turizmine ilişkin yayınların incelenmesinin faydalı olacağı düşünülmektedir. Bu çalışmada, ileride bu alanda çalışmak isteyen araştırmacılar için yol gösterici bilgiler verilerek araştırmacılara kolaylık sağlayacağı düşünülmektedir.

\section{Kavramsal Çerçeve}

\subsection{Kış Turizmi}

Doğaya duyarlı ve sürdürülebilirlik anlayışı çerçevesinde gelişen ve alternatif turizm çeşitlerinden biri olan kış turizmi (Baytok ve diğ., 2017), elverişli kar koşullarına bağlı olup (Bürki ve diğ.,2007), snowboard ve kayak sporu gibi spor faaliyetlerini içeren bir turizm türüdür (Tervo, 2008). Bu nedenle belirli bir yüksekliğe sahip ve kayak yapmaya 
elverişli yerler, kış turizminin gelişebildiği yerlerdendir (Altaş ve diğ., 2015: 346).Kış sporları ve kayak merkezleri, yüksek ve dağlık alanlarda gerçekleşen kış turizminin önemli unsurlarındandır (Akova, 2000). Konaklama ve ulaşım, kış turizmi açısından oldukça önemlidir. Belli yükseklikteki dağlarda konaklama tesisleri kurmak ve bu tesislerin kaliteli hizmet vermesini sağlamak gerekmektedir. Ayrıca karlı ve engebeli arazilerde ulaşımın sorunsuz bir şekilde 24 saat sağlanması kış turizminin ayrılmaz bir parçasıdır (İncekara, 1998).

Dünya'da en bilinen kış turizmi merkezi Alp dağlarıdır (Klasz ve diğ., 2017). Ancak, son zamanlarda teknolojinin gelişmesi ile birlikte buzdan inşa edilen oteller, barlar ve hatta köyler de dikkat çekmektedir. Buz mimarisinin yaygın olduğu ülkeler Norveç, İsveç, Finlandiya, Danimarka, İzlanda, Grönland, İskoçya, Svalbard ve Kanada gibi Kuzey Kutup Dairesine yakın olan ülkelerdir (Genç, 2019).Ülkemizde ise kış turizmi faaliyetlerinin sürdüğü Uludağ, Kartalkaya, Palandöken, Erciyes, Sarıkamış gibi kayak merkezlerinin yanında henüz turizme kazandırılmamış pek çok kayak merkezi de bulunmaktadır (Şenol, 2008).

Literatürde kış turizmi ile ilgili çalışmalar incelendiğinde, kış turizminin turistik bir ürün olarak değerlendirildiği ve kış turizmi ile ilgili turistik ürün çeşitlendirilmesi çalışmalarının olduğu görülmektedir (Osmund ve Sunday, 2010; Mursalov, 2009). Ayrıca kış turizmine katılan turistlerin motivasyonlarını inceleyen araştırmalar (Matzler ve Siller, 2003; Cocolas ve diğ., 2016) ile iklim ve iklim değişikliğinin kış turizmine etkisi konuları (Koenig ve Abegg, 1997; Scott ve diğ., 2008b) hakkında da literatürde araştırmalar mevcuttur. Bunun yanında kış turizmine katılan turistlerin kış turizmine yönelik tutumları (Christopoulou ve Papadopoulos, 2001; Pickering ve diğ., 2010), seyahat motivasyonları (Alexandris ve diğ., 2009; Van der Merwe ve Saayman, 2008) ve kış turizminin bölgesel ekonomiye etkileri (Pütz ve diğ., 2011) konuları da araştırılmıştır.

İklim değişikliği ve kış turizmi ile ilişkili çalışmalar bilim insanları tarafından çokça araştıılan konular içerisinde yer almıştır (Tervo, 2008: 317). Iklim-turizm ve iklim değişikliği-kış turizmi konuları üzerine yapılan araştırmaların (Agrawala, 2007; Brouder ve Lundmark., 2011; Soboll ve Dingeldey., 2012; Dar ve diğ., 2014)yanında küresel ısınmanın kış turizmi üzerindeki etkileri (Breiling ve Charamza, 1999; Damm ve diğ., 2017; Yang ve Wan, 2010; Falk ve Lin, 2018) de incelenmiştir. İklim değişikliğinin turizmi etkilemesi, karar vericilerin ve turistlerin farklı koşullara uyum sağlamasına yol açmıştır (Elsasser ve Bürki, 2002). Ayrıca iklimin, zaman içinde turizmin mevsimsellik özelliğini etkileyeceği ve destinasyonlar üzerinde bir değişikliye yol açacağı konusu tartışılmakta olup bu durum sonucunda da rekabetin artması beklenmektedir (Hewer ve Gough, 2018).

\subsection{Bibliyometrik Çalışmalar}

Atıf, yayın sayısı gibi metin tabanlı veriler temelinde bilimsel yayınların verimliliğini ölçmek mümkündür. Ülkeler, disiplinler ve yazarlar hakkındaki verimliliği ve bilgi akışını ölçmek için de çeşitli yöntemler geliştirilmiştir (Kurtz ve Bollen, 2010). Bibliyometrik analiz yöntemindeise belirli bir alan ya da araştırma konusu ile ilgili çalışmalar incelenmektedir (Van Raan, 2005). Bibliyometrik analiz kavramı ilk olarak Alan Pritchard tarafından 1969 yılında kullanılmıştır (Thanuskodi, 2011). Bibliometrik analiz teknikleri, genellikle değerlendirme ve ilişkisel yaklaşımlar şeklinde ikiye ayrılmaktadır (Jiang ve diğ., 2019). Bibliyometrik analizde sıklık analizi ve diğer temel istatistikler kullanılarak araştırmalar yapılmaktadır. Çalışmaların genel olarak değerlendirilmesi için nitel bir yaklaşım da kullanılmaktadır. Bir diğer yöntemde ise ilişkisel sonuçları ortaya 
koymak için kullanılan ilişkisel istatistik analizleri tercih edilmektedir (Köseoğlu ve diğ, 2016). Bibliyometrik çalışmaların turizm çalışmalarında da kullanıldığı görülmekte ve bu durum genellikle dergilerin ve yayınların değerlendirilmesi ile ilgili olmaktadır (Hall, 2001). Bazı çalışmalarda dergilerdeki genel durum tespit edilmekte ve dergilerin gelişme süreci takip edilmektedir (Çiçek ve Kozak, 2012). Uluslararası literatür incelendiğinde, turizm ve konaklama endüstrisi ile ilgili yapılan bibliyometrik bilimsel çalışmalar; dergilerin değerlendirilmesi, makale analizi, içerik analizi, atıf analizi, disiplinler arası ilişki analizi ve ülke düzeyinde araştırma analizi olmak üzere çeşitli kategorilerde incelenmektedir (Köseoğlu ve diğ., 2015). Uluslararası literatürde yayımlanan turizm ile ilgili bibliyometrik çalışmalar içerisinde; destinasyon yönetimi (Capone, 2015), sürdürülebilir turizm trendleri (Ruhanen ve diğ., 2015), turizm ve konaklama alanında inovasyon (Gomezelj, 2016), turizm ve cinsiyet (Figueroa-Domecq ve diğ., 2017), macera turizmi (Cheng vd., 2018), kriz yönetimi ve turizm (Jiang ve diğ., 2019) ile turizm ve restoran (Rodriguez-Lope ve diğ., 2019) konulu araştırmaların olduğu görülmüştür.

Ulusal literatürde ise bazı çalışmalarda farklı disiplinlerde yer alan kavramlar ile turizm ilişkisini inceleyen bibliyometrik çalışmalar yapılmıştır. Turizm ve kültürel miras (Toksöz ve Birdir, 2016), turizm ve suç (Alp ve Ünlü, 2019), turizm ve festival (Boyacıoğlu ve Elmas, 2019), turizm ve liderlik (Çelik, 2019), turizm ve girişimcilik (Işık ve diğ., 2019), turizm ve yiyecek tüketimi (Nebioğlu, 2019) ile turizm ve iklim değişikliği (Polat ve diğ., 2019) kavramlarını birlikte ele alan çalışmaların bibliyometrik analizi yapılmıştır. Bunun yanında kitle turizmi dışındaki alternatif turizm türleri ile turizmin olgusal kavramları ile ilgili yayınlar da bibliyometrik analiz ile değerlendirilmiştir. Örneğin; sağlık turizmi (Temizkan ve diğ., 2015), alternatif turizm (Düşmezkalender ve Metin, 2019) ve sürdürülebilir turizm (Yeksan ve Akbaba, 2019) konulu araştırmalar bibliyometrik analize tabi tutularak incelenmiştir. Benzer şekilde Tayfun ve arkadaşları (2016), 1985-2016 yılları arasında yayımlanan ve turizmi konu alan 367 lisansüstü tezin belirli özelliklere göre bibliyometrik analizini yapmışlardır. Bu çalışmada yüksek lisans tezlerinin doktora tezlerinden daha fazla olduğu, en çok eğitim bilimleri enstitüsü tarafından turizm ile ilgili tezlerin yayımlandığı sonucuna ulaşılmıştır. Ayrıca Sünnetçioğlu ve arkadaşları (2017) da gastronomi tezlerini incelemiş ve gastronominin pazarlama yönüyle değerlendirildiğini belirtmiştir. Olcay ve arkadaşları (2018) tarafından ise helal turizm konusunda yapılmış çalışmaların bibliyometrik analizi yapılmış ve 50 adet tez, makale ve bildiriye ulaşılmıştır. Genellikle, likert tipi ölçeklerin çalışmalarda kullanıldığı belirlenmiştir. Aydın ve Aksöz (2019), turizm destinasyonu alanında yayımlanmış ulusal tezleri incelemiş ve nicel araştırma yöntemlerinin yüksek lisans düzeyindeki tezlerde daha çok tercih edildiğini belirtirken nitel araştırma yöntemlerinin daha çok doktora tezlerinde kullanıldığını tespit etmiştir. Gümüş ve Yeksan (2019) ise ulusal turizm kongrelerinde örgütsel davranış alanı konularını içeren bildirileri incelemiş ve en fazla çalışılan örgütsel davranış konularının iş tatmini ve örgütsel bağlılık olduğu belirtilmiştir.

\section{Yöntem}

$\mathrm{Bu}$ çalışmada, kış turizmine ilişkin yayınların bibliyometrik analiz yöntemi ile çeşitli parametreler açısından incelenmesi amaçlanmıştır. Bu bağlamda, kış turizmine ilişkin yayınlar; atıf ağı, dergi ve ülke iş birliktelikleri ile anahtar kelimeler ağı parametreleri açısından değerlendirilmiştir. Çalışmada, betimsel bir analiz yöntemi seçilmiştir. Veriler, Web of Science Core Collection veri tabanı aracılığı ile toplanmış ve Citespace II analiz programı ile analize edilmiştir. Citespace II programı, modelleme ve görselleştirme süreci olan bir Java uygulaması olup, bir bilgi alanında ortaya çıkan eğilimlerin analizini kolaylaştırmayı amaçlamaktadır (Chen, 2006:393). 
Bibliyometrik analizde kullanılan bazı kavramlar şu şekildedir; merkezilik derecesi, düğüm, yoğunluk, mean silhouette ve modularity değeridir. Bu kavramların açıklanmasının analizin anlaşııması açısından önem arz ettiği düşünülmektedir.

- Merkezilik derecesi, yazarın veya herhangi bir düğümün ne ölçüde merkezi konumda olduğunu belirtmekte ve bu durum da ağın işlevinin değerlendirilmesi açısından yararlı bir görünüm sunmaktadır (Bazm ve diğ., 2016). Başka bir ifade ile merkezilik derecesi, bir düğümün ağdaki diğer düğümlerle olan bağlarının sayısıdır.

-Yoğunluk, bir araştırma alt alanı içindeki çeşitli akışların derecelerini ifade etmektedir (Vogel ve Güttel, 2013: 430).

- Mean silhouette değeri, -1 ile 1 arasında değer alabilir ve kümelerdeki belgelerin diğer belgeler ile olan benzerliğini açıklamaktadır (Zhang ve diğ., 2010: 691).

- Modularity değeri, kümeler içindeki düğümlerin diğer kümeler ile olan bağlantılarını ortaya koymaktadır (Takeda ve Kajikawa, 2010).

Araştırmada, Web of Science Core Collection veri tabanında "kış turizmi"ve "kayak turizmi" anahtar kelimelerin İngilizcesi olan "winter tourism" ve "ski tourism" kelimeleri yazılarak birlikte taranmıştır. Toplamda 218 adet makaleye ulaşılmış ve söz konusu yayınların hepsi analiz edilmiştir. Araştırmada, bibliyometrik analiz sonucu elde edilmesi amaçlanan temel parametreler şu şekildedir:

$>$ Kış turizmi yayınlarının en çok atıf alan yazarlara göre dağılımı ve yazar ortak atıf ağı,

$>$ Kış turizmi yayınlarının en çok atıf alan yayınlara göre dağılımı ve yayın ortak atıf ağı,

$>$ Kış turizmi yayınlarının en çok atıf alan dergilere göre dağılımı ve dergi ortak atıf ağı,

> Kış turizmi yayınlarına odaklanan ülkeler ve bu ülkeler arasındaki iş birliktelikleri,

> Kış turizmi yayınlarında kullanılan anahtar kelimeler ve bu anahtar kelimeler ile ilgili ağ grafiği sonuçlarına ulaşıması amaçlanmıştır.

\section{Bulgular}

$\mathrm{Bu}$ bölümde kış turizmi ile ilgili Web of Science veri tabanında yer alan makalelerin çeşitli parametreler açısından bibliyometrik analiz sonuçlarına yer verilmiştir. Tablo 1'e göre kış turizmine ilişkin makalelerin yıllara göre dağılımı on yıllık periyotlar halinde gösterilmekte ve en çok yayın yayımlanan dönemin 2011 yılı itibariyle günümüze kadar olan süreci kapsadığı anlaşılmaktadır. Ancak 1980-1990 yılları arasında yayımlanan yayınlar, bütün yayınların sadece \%1'ini oluşturmaktadır. Buna göre, kış turizmi ile ilgili yayınların son yıllarda ilgi gören bir konu olduğu söylenebilir.

Tablo 1: Yıllara Göre Yayınların Dağılımı

\begin{tabular}{|c|c|c|}
\hline YII & Frekans & $\%$ \\
\hline $\mathbf{2 0 1 1 - 2 0 2 0}$ & 175 & $80 \%$ \\
\hline $\mathbf{2 0 0 1 - 2 0 1 0}$ & 37 & $17 \%$ \\
\hline $\mathbf{1 9 9 1 - 2 0 0 0}$ & 4 & $2 \%$ \\
\hline $\mathbf{1 9 9 0 - 1 9 8 0}$ & 2 & $1 \%$ \\
\hline Toplam & 218 & $100 \%$ \\
\hline
\end{tabular}


Tablo 2'de, kış turizmine ilişkin 218 çalışma içerisinde en çok atıf alan yazarlara ve merkezilik derecelerine yer verilmiştir. Buna göre, en fazla atıf yapılan yazarın Scot, D. $(n=101)$ olduğu belirlenirken, merkezilik derecesi en yüksek olan ve ortak atıf yapılan eserin Intergovernmental Panel on Climate Change (IPCC) tarafından yayınlanan rapor $(n=0.22)$ olduğu görülmektedir. Bu bağlamda, IPCC'nin atıf almada temel kaynaklardan biri olduğu düşünülebilir.

Tablo 2: Ortak Atıf Yapılan Yazarların Atıf Sayıları ve Merkezilik Dereceleri

\begin{tabular}{|l|c|c|c|l|c|c|c|}
\hline \multicolumn{1}{|c|}{ Yazar } & $\begin{array}{c}\text { Atıf } \\
\text { Sayısı }\end{array}$ & Yıl & Küme\# & \multicolumn{1}{|c|}{ Yazar } & $\begin{array}{c}\text { Merkezilik } \\
\text { Derecesi }\end{array}$ & Yıl & Küme\# \\
\hline Scott D. & 101 & 2007 & 8 & IPCC & 0.22 & 2001 & 8 \\
\hline Steiger R. & 82 & 2011 & 6 & Abegg B. & 0.19 & 1999 & 15 \\
\hline Abegg B. & 77 & 1999 & 15 & Hudson S. & 0.11 & 2006 & 10 \\
\hline Elsasser .H & 68 & 2007 & 7 & Beniston M. & 0.09 & 2007 & 7 \\
\hline Dawson J. & 64 & 2012 & 4 & Unbehaun W. & 0.08 & 2012 & 3 \\
\hline Falk M. & 50 & 2013 & 5 & Koenig U. & 0.08 & 2009 & 7 \\
\hline Gossling S. & 44 & 2008 & 8 & Gossling S. & 0.06 & 2008 & 8 \\
\hline Beniston M. & 41 & 2007 & 7 & BREILING M. & 0.06 & 1999 & 13 \\
\hline Hamilton LC. & 37 & 2008 & 7 & Hall CM. & 0.06 & 2002 & 12 \\
\hline Vanat L. & 34 & 2013 & 5 & Elsasser H. & 0.05 & 2007 & 7 \\
\hline
\end{tabular}

Şekil 1: Yazar Ortak Atıf Ağı

Eite Space, v. 5.6.R2 (64-bit)

\section{Sespacelwinter 2020 idats}

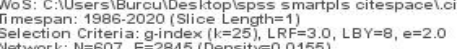

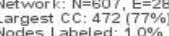

Iodes Labeled:
runing: None

Şekil 1'de, bilimsel haritalama yöntemi ile gerçekleştirilen yazar ortak atıf ağı sunulmuştur. Yazar ortak atıf ağı, 607 düğüm (atıf kaynağı yazarlar), 2845 bağlantı ve 46kümeden oluşmuştur. Yoğunluğu 0.0155 'ir. Mean silhouette değeri ise 0.5351, modularity değeri $Q=0.6116$ bulunmuştur. Buna göre ağ değerinin homojene yakın bir değer aldığı ve güçlü bir kümelenmeye sahip olduğu söylenebilir.

Yazarların atıf patlama değerlerinin verildiği tablo 3'te, Pickering, C.'nin 20132016 yılları arasındaki atıf patlama değeri 6.2 olarak hesaplanmıştır. Yazar, 2013-2016 yılları arasında yayımlanmış yayınlar içerisinde atıf almada öne çıkan yazarlardan biri 
olmuştur. Bunun yanında son yıllardaki atıf patlama değerleri incelendiğinde ise Damm A.'nın (4.76) 2018-2020 yılları arasındaki atıf patlama değerleri ile Falk, M.'nin (4.08) 2018-2020 yılları arasındaki atıf patlama değerleri en güncel atıf patlama değerleri olarak görülmektedir.

Tablo 3: Yazarların Yıllara Göre Atıf Patlama Değerleri

\begin{tabular}{|l|c|c|c|l|}
\hline \multicolumn{1}{|c|}{ Yazar } & Patlama & Başlangıç & Bitiş & 1986 - 2020 \\
\hline Pickering C. & 6.2229 & 2013 & 2016 & \\
\hline Breiling M. & 5.9067 & 2007 & 2012 & \\
\hline Elsasser H. & 5.5067 & 2007 & 2012 & \\
\hline Damm A. & 4.7664 & 2018 & 2020 & \\
\hline Konu H. & 4.7242 & 2017 & 2020 & \\
\hline Damm A. & 4.6649 & 2016 & 2020 & \\
\hline IPCC & 4.6615 & 2001 & 2012 & \\
\hline Hendrikx J. & 4.1545 & 2015 & 2017 & \\
\hline Falk M. & 4.0883 & 2018 & 2020 & \\
\hline Unbehaun W. & 4.0317 & 2012 & 2015 & \\
\hline Gilaberte- & 3.9929 & 2017 & 2020 & \\
Burdalo M. & 3.773 & 2017 & 2020 & \\
\hline Gonseth C. & 3.744 & 2013 & 2016 & \\
\hline Bicknell S. & 3.7317 & 2013 & 2017 & \\
\hline Moen J. & & & \\
\hline
\end{tabular}

Bibliyometrik analiz sonucunda atıf kaynaklarının aldıkları atıf sayıları tablo 4'teverilmiştir. Kış turizmine ilişkin atıf kaynaklarının atıf sayıları incelendiğinde, küme\#5'de bulunan Steiger, R (2011) tarafından yayımlanan makalenin en fazla atıf $(n=34)$ alan makale olduğu bulgusuna ulaşılmıştır. Buna göre en fazla atıf yapılan yayının ilgili alanda önemli bir bilgi kaynağı ve yol gösterici bir kaynak olduğu söylenebilir. Ayrıca ikinci sırada yer alan kaynağın Dawson, D. ve Scott D. (2013) tarafından yayımlanan makale olduğu ve en çok atıf alan makaleler içerisinde en güncel kaynak olduğu anlaşılmıştır.

Tablo 4: Atıf Kaynaklarının Aldıkları Atıf Sayıları

\begin{tabular}{|l|c|c|c|}
\hline Yayın Adı & Frekans & Yılı & Küme \\
\hline $\begin{array}{l}\text { Steiger, R. The impact of snow scarcity on ski tourism: An } \\
\text { analysis of the record warm season 2006/2007 in Tyrol } \\
\text { (Austria). }\end{array}$ & 34 & 2011 & 5 \\
\hline $\begin{array}{l}\text { Dawson, J., ve Scott, D. (2013). Managing for climate change in } \\
\text { the alpine ski sector. }\end{array}$ & 33 & 2013 & 4 \\
\hline $\begin{array}{l}\text { Töglhofer, C., Eigner, F., ve Prettenthaler, F. (2011). Impacts of } \\
\text { snow conditions on tourism demand in Austrian ski areas. }\end{array}$ & 32 & 2011 & 5 \\
\hline
\end{tabular}


Tablo 4'ün devamı

Steiger, R. (2010). The impact of climate change on ski season length and snowmaking requirements in Tyrol, Austria.

Dawson, J., Scott, D., ve McBoyle, G. (2009). Climate change analogue analysis of ski tourism in the northeastern USA.

Pickering, C. (2011). Changes in demand for tourism with climate change: a case study of visitation patterns to six ski resorts in Australia.

Abegg, B., Agrawala, S., Crick, F., ve de Montfalcon, A. (2007). Climate change impacts and adaptation in winter tourism. Climate change in the European Alps: Adapting winter tourism and natural hazards management, Rixen, C., Teich, M., Lardelli, C., Gallati, D., Pohl, M., Pütz, M., ve Bebi, P. (2011). Winter tourism and climate change in the Alps: an assessment of resource consumption, snow reliability, and future snowmaking potential.

Gössling, S., Scott, D., Hall, C. M., Ceron, J. P., ve Dubois, G. (2012). Consumer behaviour and demand response of tourists to climate change. Annals of tourism research, 39(1), 36-58.

Scott, D., Dawson, J., ve Jones, B. (2008). Climate change vulnerability of the US Northeast winter recreation-tourism sector.

Atıf kaynaklarının merkezilik dereceleri tablo 5'te yer verilmiştir. Buna göre, tabloda, merkezilik derecesi en yüksek ilk 10 kaynağa bakıldığında, ilk sırada yer alan kaynağın, Organisation for Economic Co-operation and Development (OECD) tarafından 2007 yılında yayımlanan yayın (0.11) olduğu ikinci sıradaki kaynağın ise Steiger, R. tarafından 2010 yılında yayımlanan makale (0.10) olduğu görülmektedir. Merkezilik derecesi en yüksek iki kaynağın, iklim değişikliği ve kış turizmi konularını ele aldığı görülmektedir. Kış turizminin iklim değişiklinden büyük ölçüde etkilenmesi, söz konusu bu kaynakların önemli referans kaynakları olmasına yol açmıştır.

Tablo 5: Atıf Kaynaklarının Merkezilik Dereceleri

\begin{tabular}{|l|c|c|c|}
\hline Yayın Adı & $\begin{array}{c}\text { Merkezilik } \\
\text { Derecesi }\end{array}$ & Yıl & Küme \# \\
\hline $\begin{array}{l}\text { OECD (2007) Climate Change in the European Alps: adapting winter } \\
\text { tourism and natural hazards management. }\end{array}$ & 0.11 & 2007 & 4 \\
\hline $\begin{array}{l}\text { Steiger, R. (2010) The impact of climate change on ski season length } \\
\text { and snowmaking requirements in Tyrol, Austria. }\end{array}$ & 0.10 & 2010 & 4 \\
\hline $\begin{array}{l}\text { Gössling, S., Scott, D., Hall, C. M., Ceron, J. P., ve Dubois, G. (2012). } \\
\text { Consumer behaviour and demand response of tourists to climate } \\
\text { change. }\end{array}$ & 0.07 & 2012 & 4 \\
\hline $\begin{array}{l}\text { Dawson, J., ve Scott, D. (2013). Managing for climate change in the } \\
\text { alpine ski sector. }\end{array}$ & 0.06 & 2013 & 4 \\
\hline $\begin{array}{l}\text { ACACIA, (2000) Tourism and Recreation, in M. Parry (ed.) Assessment } \\
\text { of Potantial Effects and Adaptations for Climate Change in Europe. }\end{array}$ & 0.06 & 2000 & 7 \\
\hline $\begin{array}{l}\text { Töglhofer, C., Eigner, F., ve Prettenthaler, F. (2011). Impacts of snow } \\
\text { conditions on tourism demand in Austrian ski areas. }\end{array}$ & 0.05 & 2011 & 5 \\
\hline $\begin{array}{l}\text { Bark, R. H., Colby, B. G., ve Dominguez, F. (2010). Snow days? } \\
\text { Snowmaking adaptation and the future of low latitude, high elevation } \\
\text { skiing in Arizona, USA. }\end{array}$ & 0.05 & 2010 & 5 \\
\hline $\begin{array}{l}\text { Agrawala, S. (2007). Climate change in the European Alps: adapting } \\
\text { winter tourism and natural hazards management. }\end{array}$ & 0.05 & 2007 & 6 \\
\hline $\begin{array}{l}\text { Scott, D., ve McBoyle, G. (2007). Climate change adaptation in the ski } \\
\text { industry. Mitigation and adaptation strategies for global change. }\end{array}$ & 0.05 & 2007 & 7 \\
\hline $\begin{array}{l}\text { NSAA (2005) Kottke national end of season survey 2004/05(26th edn.). } \\
\text { NSAA. }\end{array}$ & 0.05 & 2005 & 8 \\
\hline
\end{tabular}




\section{Şekil 2: Yayın Ortak Atıf Ağı

Şekil 2'de yayın ortak atıf ağı görseline yer verilmiştir. Yayın ortak atıf ağı, 618 düğüm, 2506 bağlantı ve 94 kümeden oluşmaktadır. Yoğunluğu 0.0131, modularity değeri $\mathrm{Q}=0.725$ ve mean silhouette değeri ise 0.4079 şeklinde hesaplanmıştır. Bu sonuçlara göre, ağın homojen değerler aldığı ve yeterli sayıda kümeye sahip olduğu söylenebilir.

Tablo 6: Atıf Kaynaklarının Yıllara Göre Atıf Patlama Değerleri

\begin{tabular}{|c|c|c|c|c|}
\hline & Patlama & Başlangıç & Bitiş & \\
\hline $\begin{array}{l}\text { Steiger, R., Scott, D., Abegg, B., Pons, M., ve Aall, C. } \\
\text { (2019). A critical review of climate change risk for ski } \\
\text { tourism. }\end{array}$ & 7.5438 & 2018 & 2020 & 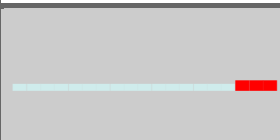 \\
\hline $\begin{array}{l}\text { Unbehaun, W., Pröbstl, U., ve Haider, W. (2008). Trends in } \\
\text { winter sport tourism: challenges for the future. }\end{array}$ & 6.8668 & 2012 & 2015 & \\
\hline $\begin{array}{l}\text { Scott, D., McBoyle, G., ve Mills, B. (2003). Climate change } \\
\text { and the skiing industry in southern Ontario (Canada): } \\
\text { exploring the importance of snowmaking as a technical } \\
\text { adaptation. }\end{array}$ & 6.1836 & 2007 & 2011 & \\
\hline $\begin{array}{l}\text { Agrawala, S., Crick, F., ve de Montfalcon, A. (2007). Climate } \\
\text { change impacts and adaptation in winter tourism. Climate } \\
\text { change in the European Alps: Adapting winter tourism and } \\
\text { natural hazards management, }\end{array}$ & 5.9952 & 2008 & 2015 & \\
\hline $\begin{array}{l}\text { Scott, D., McBoyle, G., Minogue, A., ve Mills, B. (2006). } \\
\text { Climate change and the sustainability of ski-based tourism in } \\
\text { eastern North America: A reassessment, }\end{array}$ & 5.7024 & 2012 & 2014 & \\
\hline
\end{tabular}




\section{Tablo 6'nın devamı}

\begin{tabular}{l|l|l|l|l|}
\hline $\begin{array}{l}\text { Dawson, J., Scott, D., ve McBoyle, G. (2009). Climate } \\
\text { change analogue analysis of ski tourism in the northeastern } \\
\text { USA. }\end{array}$ & 5.6279 & 2012 & 2017 & \\
\hline $\begin{array}{l}\text { Scott, D., McBoyle, G., ve Minogue, A. (2007). Climate } \\
\text { change and Quebec's ski industry. }\end{array}$ & 5.2007 & 2009 & 2015 & \\
\hline $\begin{array}{l}\text { Pickering, C. M., Castley, J. G., ve Burtt, M. (2010). Skiing } \\
\text { less often in a warmer world: Attitudes of tourists to climate } \\
\text { change in an Australian skiresort. }\end{array}$ & 5.1825 & 2013 & 2016 & \\
\hline $\begin{array}{l}\text { Damm, A., Greuell, W., Landgren, O., ve Prettenthaler, F. } \\
\text { (2017). Impacts of+ } 2 \text { C global warming on winter tourism } \\
\text { demand in Europe. }\end{array}$ & 5.1363 & 2018 & 2020 & \\
\hline $\begin{array}{l}\text { Damm, A., Köberl, J., ve Prettenthaler, F. (2014). Does } \\
\text { artificial snow production pay under future climate } \\
\text { conditions?A case study for a vulnerable ski area in Austria. }\end{array}$ & 5.0335 & 2016 & 2020 & \\
\hline
\end{tabular}

Atıf kaynakların atıf patlama değerleri incelendiğinde ise, en yüksek değerin 2018-2020 yılları arasında Steiger, R. ve arkadaşlarına (7.54) ait olduğu görülmektedir. Steiger, R. ve arkadaşları tarafından 2019 yılında yayımlanan ve iklim değişikliğinin kayak turizmi üzerindeki etkilerinin araştırıldığı makalenin 2018-2020 yılları arasında literatürde etkili olduğu söylenebilir. Referans kaynağın, atıf patlama değerleri içerisinde en güncel makale olması ve aynı zamanda en yüksek atıf patlama değerine sahip olması, çalışmanın alanda dikkat çeken bir kaynak olduğu düşüncesini akla getirmektedir.

Tablo 7: Ortak Atıf Alan Dergilerin Atıf Sayıları ve Merkezilik Dereceleri

\begin{tabular}{|c|c|c|c|c|c|c|c|}
\hline Dergi Adı & YII & Frekans & Küme \# & Dergi Adı & YII & Merkezilik & Küme \# \\
\hline $\begin{array}{l}\text { Tourism } \\
\text { Management }\end{array}$ & 2008 & 111 & 9 & $\begin{array}{l}\text { Mountain Research } \\
\text { and Development }\end{array}$ & 2002 & 0.19 & 14 \\
\hline Climatic Change & 1999 & 96 & 17 & Climatic Change & 1999 & 0.16 & 17 \\
\hline Climate Research & 2003 & 88 & 13 & $\begin{array}{l}\text { Ornithologische } \\
\text { Beobachter }\end{array}$ & 1986 & 0.15 & 25 \\
\hline $\begin{array}{l}\text { Mountain Research } \\
\text { and Development }\end{array}$ & 2002 & 88 & 14 & NFP 31 & 1999 & 0.14 & 12 \\
\hline Climate Research & 2003 & 77 & 11 & $\begin{array}{l}\text { Annals of Tourism } \\
\text { Research }\end{array}$ & 2006 & 0.12 & 11 \\
\hline $\begin{array}{l}\text { Journal of } \\
\text { Sustainable Tourism }\end{array}$ & 2012 & 77 & 4 & $\begin{array}{l}\text { Journal of Applied } \\
\text { Ecology }\end{array}$ & 2007 & 0.12 & 4 \\
\hline $\begin{array}{l}\text { Annals of Tourism } \\
\text { Research }\end{array}$ & 2006 & 68 & 11 & $\begin{array}{l}\text { Biological } \\
\text { Conservation }\end{array}$ & 2003 & 0.11 & 8 \\
\hline Tourism Review & 2012 & 65 & 4 & $\begin{array}{l}\text { Scandinavian Journal } \\
\text { of Hospitality and } \\
\text { Tourism }\end{array}$ & 2013 & 0.09 & 5 \\
\hline $\begin{array}{l}\text { International Journal } \\
\text { of Climatology }\end{array}$ & 2008 & 64 & 8 & $\begin{array}{l}\text { Regional } \\
\text { Environmental } \\
\text { Change }\end{array}$ & 2008 & 0.08 & 7 \\
\hline $\begin{array}{l}\text { European Journal of } \\
\text { Climate Change }\end{array}$ & 2008 & 62 & 7 & $\begin{array}{l}\text { A Journal of the } \\
\text { Human Environment }\end{array}$ & 2010 & 0.08 & 6 \\
\hline
\end{tabular}


Tablo 7'de ise kış turizmi araştırmalarını yayımlayan dergiler üzerine bir analiz gerçekleştirilmiştir. Analizde dergilerin ortak atıf sayıları ve merkezilik dereceleri belirlenmiştir. Kış turizmi ile ilgili makalelerin yayımlandığı dergiler içerisinde ortak atıf sayısı en fazla olan derginin Tourism Management dergisi $(n=111)$ olduğu sonucuna ulaşılırken ağda en fazla merkezilik derecesine sahip derginin Mountain Research and Development dergisi (0.19) olduğu tespit edilmiştir.

\section{Şekil 3: Dergi Ortak Atıf Ağı}

CiteSpace, V. 5.6.R2 (64-bit)
April 8, 2020 6:26:46 PM EET

imespan: 1986 .

Selection Criteria: g-index $(k=25), L R F=3.0, L B Y=8, e=2.0$

Network: $N=581, E=2962$ (Density $=0.0176$ )

Largest CC: $502(86 \%)$

runing: None

Dergi ortak atıf ağı şekil 3"te sunulmuştur. Ağ,581 düğüm, 2962 bağlantı ve 42 kümeden oluşmaktadır. Ağın yoğunluğu 0,0176; mean silhouette değeri 0,4934 modularity değeri de $Q=0,6035^{\prime \prime} t i r$. Atıf patlama değerlerinin verildiği tablo 8'de ise, en yüksek patlama değeri, ismi belirlenememiş anonim bir derginindir (9.18). En yüksek ikinci patlama değerine sahip dergi ise Current Issues in Tourism (6.21) dergisi olup 2018-2020 yılları arasında kış turizmi çalışmaları için önemli bir kaynak olmuştur.

Tablo 8: Dergilerin Yıllara Göre Atıf Patlama Değerleri

\begin{tabular}{|l|c|c|c|l|}
\hline \multicolumn{1}{|c|}{ Dergi Adı } & Patlama & Başlangıç & Bitiş & 1986 - 2020 \\
\hline Anonim & 9.8103 & 2007 & 2013 & \\
\hline Current Issues in Tourism & 6.2168 & 2018 & 2020 & \\
\hline Geographical Research & 5.177 & 2013 & 2016 & \\
\hline Journal of Applied Ecology & 5.1414 & 2007 & 2011 & \\
\hline Global Environmental Change & 4.8667 & 2009 & 2015 & \\
\hline Tez & 4.4856 & 2015 & 2018 & \\
\hline The journal Climate Services & 4.203 & 2018 & 2020 & \\
\hline Journal of Hospitality Marketing & 4.0298 & 2016 & 2018 & \\
and Management & & & & \\
\hline Environmental Science and Policy & 4.0289 & 2017 & 2020 & \\
\hline Klimaanderung und Tourismus. & 3.7276 & 2011 & 2014 & \\
\hline
\end{tabular}


Tablo 9'da kış turizmi araştırmalarının ülke iş birliklerine ilişkin ağ bilgileri sunulmuştur. Buna göre, en çok iş birliği yapan ülke Avusturya $(n=50)$ olurken, merkezilik derecesi en yüksek olan ülke ise İsveç (0.45) olmuştur. Bunun yanında Türkiye ise $(n=15)$ ülke iş birliktelikleri içerisinde ilk 10 ülke arasında yer almaktadır.

Tablo 9: Ülke İş Birliktelikleri ve Merkezilik Dereceleri

\begin{tabular}{|l|c|c|c|l|c|c|c|}
\hline Ülkeler & Frekans & Yıl & \#Küme & Ülkeler & Merkezilik & Yıl & \#Küme \\
\hline Avusturya & 50 & 1994 & 21 & İsveç & 0.45 & 2002 & 16 \\
\hline İsviçre & 30 & 2001 & 10 & Almanya & 0.34 & 2001 & 11 \\
\hline Almanya & 24 & 2001 & 11 & Avustralya & 0.27 & 2006 & 11 \\
\hline Kanada & 19 & 2003 & 12 & Avusturya & 0.25 & 1994 & 21 \\
\hline İspanya & 17 & 2012 & 4 & İtalya & 0.13 & 2008 & 10 \\
\hline İsveç & 16 & 2002 & 16 & İsviçre & 0.12 & 2001 & 10 \\
\hline İtalya & 16 & 2008 & 10 & Fransa & 0.11 & 2007 & 9 \\
\hline Türkiye & 15 & 2010 & 6 & Norveç & 0.09 & 2003 & 15 \\
\hline Norveç & 14 & 2003 & 15 & Sırbistan & 0.09 & 2014 & 4 \\
\hline Fransa & 13 & 2007 & 9 & Slovenya & 0.09 & 2010 & 1 \\
\hline
\end{tabular}

Ülke iş birlikleri ile ilgili yapılan ağ analizinde, 40 düğüm ve 100 bağlantıdan oluşan bir ağa ulaşıımıştır. Söz konusu ağ 9 kümeden oluşmaktadır ve yoğunluğu 0.1282 'dir. Ağın modularity değeri, $Q=0,4267$; mean silhouette değeri ise 0,5785 olarak bulunmuştur. Ağdaki düğümler ülkeleri ifade etmekte ve bağlantılar ise ülke ilişkilerini anlatmaktadır. Ağdaki turuncu renk güncel çalışmaları, pembe daireler merkeziliği ifade ederken pembe dairelerin kalınlığı ve boyutu merkezilik derecesini açıklamaktadır (Güzeller ve Çelikler, 2017).

\section{Şekil 4: Ülke İş Birliktelikleri}

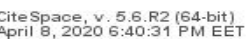

April 8, $C$ :USersiBurcuDeshtoplspss smartpls citespacel.citespacelwinter2020ldata

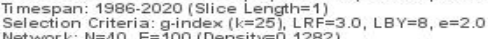

Largest CC: 34 ' $(85 \% \%)$
Nodes Labeled: $1.0 \%$
Pruning: None

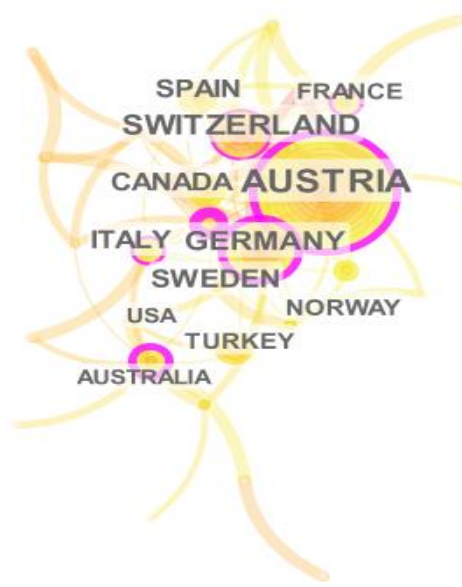

Ülkelerin atıf patlama değerlerine ise tablo 10'da yer verilmiştir. Buna göre en çok atıf patlama değerine sahip ülke İsviçre (6.14) olmuştur. Türkiye (4.33) ise 20152016 yılları arasındaki yayınları ile en çok atıf patlama değerine sahip 2. sıradaki ülkedir. Buna göre, Türkiye'nin kış turizmi çalışmaları yapan ülkeler arasında en güncel atıf kaynağına sahip ülkelerden biri olduğunu söylemek mümkündür. 
Tablo 10: Ülkelerin Yıllara Göre Atıf Patlama Değerleri

\begin{tabular}{|l|c|c|c|l|}
\hline \multicolumn{1}{|c|}{ Ülkeler } & Patlama & Başlangıç & Bitiş & \\
\hline İsviçre & 6.1439 & 2001 & 2013 & \\
\hline Türkiye & 4.3355 & 2015 & 2016 & \\
\hline Almanya & 4.15 & 2007 & 2012 & \\
\hline
\end{tabular}

Kış turizmine ilişkin çalışmalarda en çok kullanılan anahtar kelimeler ile söz konusu bu anahtar kelimelerin birbirleri ile ilişkilerini gösteren ağ görseli şekil 5 'te sunulmuştur. Ağ, 401 düğüm (anahtar kelime sayısı), 1706 bağlantı ve 55 kümeden oluşmaktadır. Ağın yoğunluğu 0,0213; mean silhouette değeri 0,4051 ve modularity değeri de 0,505"dir. Ağdaki anahtar kelimeler incelendiğinde iklim değişikliği, talep ve etki kelimelerinin ön plana çıktığı dolayısıyla kış turizminin farklı konular tarafından ele alındığı söylenebilir.

\title{
Şekil 5: Anahtar Kelime Ağı
}

Cite Space, v. 5.6. R2 (64-bit)

WoS: C:USersiBurculDesktoplspss smartpls citespacel.citespacelwinter2020ldata

Timespan: 1986-2020 (Slice Length=1)

Selection Criteria: g-index $(k=25), L R F=3.0, L B Y=8, e=2.0$

Network: $N=401, E=1706$ (Density $=0.0213$ )

Largest CC: $343(85 \%$

Pruning: None

\author{
change vulnerability \\ industry tourism \\ attitudesnowmaking behavior \\ variability impact demand \\ climate change austria \\ adaptation vulnerability \\ model weather alp
}

ski tourism

Tablo 11 'de ise kış turizmi çalışmalarında en çok kullanılan anahtar kelimeler ile ilgili bilgiler verilmiştir. En çok kullanılan anahtar kelimeler, iklim değişikliği (99), kış turizmi (71) ve etki (67) kelimeleri olmuştur. Ağdaki en merkezi anahtar kelimeler içerisinde ise; turizm (0.24), Alp Dağları (0.20) ve endüstri (0.16) kelimeleri ilk üç sırada yer almaktadır.

\section{Tablo 11: Anahtar Kelimeler ve Merkezilik Dereceleri}

\begin{tabular}{|l|l|l|l|l|l|}
\hline Kelimeler & Frekans & YII & Kelimeler & Merkezilik & YII \\
\hline İklim Değişikliği & 99 & 2002 & Turizm & 0.24 & 1993 \\
\hline Kış Turizmi & 71 & 1999 & Alp Dağları & 0.20 & 2002 \\
\hline Etki & 67 & 2008 & Endüstri & 0.16 & 2007 \\
\hline Yapay Kar & 55 & 2003 & Etki & 0.14 & 2008 \\
\hline Adaptasyon & 43 & 2003 & Kayak Turizmi & 0.12 & 2012 \\
\hline
\end{tabular}




Tablo 11'in devamı
\begin{tabular}{|l|c|c|l|l|l|}
\hline Turizm & $\mathbf{3 9}$ & $\mathbf{1 9 9 3}$ & Talep & $\mathbf{0 . 1 1}$ & $\mathbf{2 0 1 0}$ \\
\hline Endüstri & 34 & 2007 & Model & 0.10 & 2001 \\
\hline Hava Durumu & 30 & 2003 & Hava Durumu & 0.08 & 2003 \\
\hline Kayak Turizmi & 29 & 2012 & Yapay Kar & 0.08 & 2003 \\
\hline Değişkenlik & 28 & 2011 & Kış Turizmi & 0.08 & 1999 \\
\hline
\end{tabular}

Çalışmada, kış turizmi yayınları içerisinde en çok atıf alan yazar ve yayınlar ile ortak atıf ağları incelenmiştir. Ayrıca ön plana çıkan ve merkezi konumda bulunan dergi, ülke ve anahtar kelimeleri analiz edilerek ve atıf patlama değerleri belirlenmiştir. $\mathrm{Bu}$ doğrultuda kış turizminin literatürdeki yeri incelenerek alandaki genel eğilimler aktarılmaya çalışılmıştır.

\section{Tartışma ve Sonuç}

Bu çalışmada, kış turizmi ile ilgili makaleler bibliyometrik analiz yöntemi ile incelenerek kış turizmi literatüründeki mevcut durumun değerlendirilmesi amaçlanmıştır. Bu bağlamda, Web of Science veri tabanına "kış turizmi" ve "kayak turizmi" kelimelerinin İngilizcesi olan "winter tourism" ve "ski tourism" kelimeleri yazılarak taranmış ve 19862020 yılları arasında yayınlanan 218 makaleye ulaşılmıştır. Bibliyometrik analizde en çok atıf alan yazar, yayın ve dergilerin yanı sıra bu konuda en fazla iş birliği içinde bulunan ülkeler ile kullanılan anahtar kelimeler incelenmiştir.

Kış turizmi çalışmalarının bibliyometrik analiz sonuçlarına göre, 2001 yılından itibaren kış turizmi konusu üzerine yapılan çalışmalarda bir artış olduğu anlaşılmış ve 2011-2020 yılları arasında yayınlanan makalelerin $(n=175)$ tüm makalelerin \%80'inini oluşturduğu sonucuna varılmıştır. Bu bağlamda, kış turizmine yönelik akademik ilginin son yıllarda giderek arttığını söylemek mümkündür. Río-Rama ve arkadaşları (2019) tarafından yapılan çalışma ile de benzer sonuçlar elde edilmiştir. Kış turizmi araştırmalarında en çok atıf alan yazarlar incelendiğinde, Scott D.'nin 2007 yılındaki yayını 101 atıf alarak ilk sırada yer alırken, merkezilik derecesi en yüksek olan eser ise IPCC (0.22) olmuştur. Bunun yanında atıf patlama değeri en yüksek yazar ise 20132016 yılları arasındaki aldığı değer ile Pickering, C. olmuştur. En çok atıf alan kaynak Steiger, R (2011) tarafından yayımlanan ve yetersiz kar yağışının kayak turizmine etkisini inceleyen makale olmuştur. Merkezilik derecesine göre en yüksek değer alan atıf kaynağı ise OECD (2007) tarafından Alp Dağları bölgesindeki iklim değişikliğini ve kış turizminin bu duruma adaptasyonunu inceleyen çalışma olmuştur. Benzer şekilde en yüksek atıf patlama değerine sahip yayın da Steiger, R. ve arkadaşları tarafından (2019) iklim değişikliğinin kayak turizmi üzerindeki riskli etkilerinin incelendiği yayın olmuştur. Bu anlamda atıf kaynağı, merkezilik derecesi ve atıf patlama değerleri açısından ele alındığında, en çok incelenen konuların başında iklim değişikliği ve kış turizmini inceleyen çalışmalar olduğu görülmektedir. $\mathrm{Bu}$ bağlamda, literatür incelendiğinde iklim değişikliğinin Türkiye kış turizmine etkileri ve risklerini inceleyen çalışmaların (Zeydan ve Sevim, 2008; Aydemir ve Şenerol, 2014; Somuncu, 2018; Demiroğlu ve Ülgen, 2018; Yenice ve Erçoşkun, 2019) yanında Türkiye'deki kayak merkezlerinin iklim değişikliğine adaptasyonu hakkında yapılacak çalışmaların da literatüre katkı sağlayacağı düşünülmektedir.

Kış turizmi konulu çalışmaları yayımlayan dergiler açısından incelendiğinde ise Tourism Management $(n=111)$ dergisi en fazla atıf alan dergi olmuştur. Elde edilen sonuç, Türkçe makaleler içerisinde turizm pazarlamasını inceleyen Özel ve Kozak'ın çalışması (2012) ile Web of Science veri tabanında turizm ve yiyecek tüketimin kavramlarını inceleyen Nebioğlu ve Kalıpçı'nın (2020) çalışması ile de benzerlik 
göstermektedir. Mountain Research and Development dergisi de diğer dergiler ile karşılaştırıldığında en merkezi konumda yer alan dergidir. Ayrıca, kış turizmi literatüründe en verimli ve iş birlikteliği içinde bulunan ülkenin Avusturya $(n=50)$ olduğu ve ağda en merkezi olan ülkenin ise İsveç (0.45) olduğu belirlenmiştir. Ülkelerin atıf patlama değerlerine bakıldığında ise 2001-2013 yılları arasındaki aldığı değer ile İsviçre (6.14) en yüksek atıf patlama değerine sahiptir. Bunun yanında Türkiye, 4.33 atıf patlama değeri ile ikinci sırada yer alırken en verimli ilk 10 ülke içerisinde 8 . sırada yer almaktadır. Bu durum, kış turizmi üzerine çalışan ülkelerin çoğunlukla kar yağışı alan ve önemli kayak merkezleri olan ülkeler olduğunu göstermektedir. Analizin son bölümünde ise anahtar kelimeler incelenmiştir. Buna göre kış turizmi araştırmalarında sıklıkla kullanılan ilk üç kelimenin iklim değişikliği, kış turizmi ve etki kelimeleri olduğu anlaşılmıştır. Ağda, merkezi konumda olan ilk üç kelime ise; turizm, alp dağları ve endüstri kelimeleri olmuştur.

Çalışmanın literatüre sağladığı katkılardan bahsetmek faydalı olacaktır. Kış turizmini ele alan uluslararası yayınların bibliyometrik haritalama yöntemi ile incelenmesi ilgili literatürün genel yapısının ortaya konmasını sağlamış ve gelişim sürecinin izlenmesi açısından faydalı olmuştur. Bu anlamda gelecekte kış turizmi konusunda çalışmak isteyen araştırmacılar için rehber bir çalışma olduğu düşünülmektedir. Ayrıca, dünyadaki kış turizmi trendlerinin takip edilmesinin ülkemizdeki kış turizmi gelişimine de katkı sağlayacağı söylenebilir.

Son olarak araştırmanın bazı sınırılıklarından da bahsetmek gerekmektedir. $\mathrm{Bu}$ sınırlılıklardan biri, analize dahil edilen bütün yayınların internet ortamında yer alan makaleler olmasıdır. İnternet ortamında yer almayan makale, bildiri ve kitap gibi araştırmalara ulaşılamamıştır. Ayrıca veriler Web of Science veri tabanı aracılığı ile elde edilmiştir. Gelecek çalışmalarda Scopus, Science Direct ve Proquest gibi veri tabanlarında yer alan kış turizmi araştırmalarının bibliyometrik analizleri yapılabilir.

\section{Kaynakça}

Agrawala, S. (2007). Climate change in the European Alps: adapting winter tourism and natural hazards management. Organisation for Economic Cooperation and Development (OECD).

Akova, İ. (2000). Alternatif turizm olanaklarımız. Coğrafya Dergisi, 8, 71-84.

Alp, G., ve Çevik Ünlü, B. (2019). Turizm ve Suç İlişkisinin Bibliyometrik Haritalama İle Incelenmesi. Ömer Halisdemir Üniversitesi iktisadi ve İari Bilimler Fakültesi Dergisi, 12 (2), ss. 213-228.

Alexandris, K., Kouthouris, C., Funk, D., ve Giovani, C. (2009). Segmenting winter sport tourists by motivation: The case of recreational skiers. Journal of Hospitality Marketing and Management, 18(5), ss. 480-499.

Altaş, N., Altaş, N. T., Çavuş, A., Zaman, N., ve Zaman, N. (2015). Türkiye'nin Kış Turizmi Koridorunda Yeni Bir Kış Turizm Merkezi: Konaklı. Marmara Coğrafya Dergisi, (31), 345-365.

Aydemir, B., ve Şenerol, H. (2014). İklim Değişikliği ve Türkiye Turizmine Etkileri: Delfi Anket Yöntemiyle Yapılan Bir Uygulama Çalışması. Balıkesir Üniversitesi Sosyal Bilimler Enstitüsü Dergisi, 17(31), 381-416.

Aydın, B., ve Aksöz, O. E. (2019). Destinasyon Alanında Yayınlanmış Lisansüstü Tezlerin Bibliyometrik Profili. Journal of Tourism and Gastronomy Studies, 7(1), ss. 615-636.

Bark, R. H., Colby, B. G., \& Dominguez, F. (2010). Snow days? Snowmaking adaptation and the future of low latitude, high elevation skiing in Arizona, USA. Climatic Change, 102(3-4), 467-491. 
Bartolomé, A., Ramos, V., ve Rey-Maquieira, J. (2009). Residents' Attitudes Towards Diversification Sports Tourism in the Balearics. Tourism Recreation Research, 34(1), ss. 55-65.

Baytok, A., Pelit, E., ve Soybalı, H. H. (2017). Alternatif Turizm mi Turizmde Çeşitlilik mi? Kavramsal Bir Değerlendirme. Erzincan Üniversitesi Sosyal Bilimler Enstitüsü Dergisi, ss. 1-14.

Bazm, S., Kalantar, S. M., ve Mirzaei, M. (2016). Bibliometric mapping and clustering analysis of Iranian papers on reproductive medicine in Scopus database (20102014). International Journal of Reproductive BioMedicine, 14(6), ss. 371-382.

Boyacıoğlu, E. Z., ve Elmas, Ç. "Turizm ve Festival" Olgusunun Bibliyometrik Analizi. 20. Ulusal Turizm Kongresi, Eskişehir.

Brouder, P., veLundmark, L. (2011). Climate change in Northern Sweden: Intraregional perceptions of vulnerability among winter-oriented tourism businesses. Journal of Sustainable Tourism, 19(8), ss.919-933.

Breiling, M., ve Charamza, P. (1999). The impact of global warming on winter tourism and skiing: a regionalised model for Austrian snow conditions. Regional Environmental Change, 1(1), ss.4-14.

Bürki, R., Abegg, B., ve Elsasser, H. (2007). Climate change and tourism in the alpine region of Switzerland. B. içinde Amelung et al., (Editors), Climate change and tourism: assessment and coping strategiesss.165-172.

Capone, F. (2015). A bibliometric analysis on tourist destinations research: Focus on destination management and tourist cluster. In Tourist clusters, destinations and competitiveness, Routledge, ss. 29-53.

Ceylan, S., ve Demirkaya, H. (2009). Kış Turizmine Bağlı Olarak Gelişen Bir Kırsal Yerleşme: Çobanisa Köyü (Isparta). Doğu Coğrafya Dergisi, 14(21), ss.79-94.

Chen, C. (2006). CiteSpace II: Detecting and visualizing emerging trends and transient patterns in scientific literature. Journal of the American Society for Information Science and Technology, 57(3), ss.359-377

Cheng, M., Edwards, D., Darcy, S., ve Redfern, K. (2018). A tri-method approach to a review of adventure tourism literature: Bibliometric analysis, content analysis, and a quantitative systematic literature review. Journal of Hospitality and Tourism Research, 42(6), ss. 997-1020.

Christopoulou, O. G., ve Papadopoulos, I. J. (2001). Winter Tourism, Development of Mountainous Areas and Visitors' Attitudes Towards Landscape Protection. Anatolia, 12(2), ss.153-164.

Cocolas, N., Walters, G., ve Ruhanen, L. (2016). Behavioural adaptation to climate change among winter alpine tourists: An analysis of tourist motivations and leisure substitutability. Journal of Sustainable Tourism, 24(6), ss.846-865.

Cohen, E. (1987). "Alternative Tourism"A Critique. Tourism Recreation Research, 12(2), ss.13-18.

Çelik, S. (2019). "Turizm Alanında Liderlik Konusu ile İlgili Hazırlanmış Tezlere Yönelik Bibliyometrik Bir Analiz", Journal of Academic Value Studies 5(4), ss. 516-527.

Çiçek, D., ve Kozak, N. (2012). Anatolia: Turizm Araştırmaları Dergisi'nde yayımlanan hakem denetimli makalelerin bibliyometrik profili. Türk Kütüphaneciliği, 26(4), ss.734-756.

Damm, A., Greuell, W., Landgren, O., ve Prettenthaler, F. (2017). Impacts of +2 C global warming on winter tourism demand in Europe. Climate Services, 7, ss.3146.

Dar, R. A., Rashid, I., Romshoo, S. A., ve Marazi, A. (2014). Sustainability of winter tourism in a changing climate over Kashmir Himalaya. Environmental monitoring and assessment, 186(4), ss.2549-2562.

Demir,M. (2019). "Türkiye'de Kış Turizmine Yabancı Turist İlgisi”. İçinde Çavuş, A. (Editör),Farklı Perspektiflerden Kış Turizm, ss.70-89, Paradigma Akademi. 
Demiroğlu, O. C., ve Ülgen, İ. G. (2018). İklim Değişikliği ve Turizm: Genişletilmiş Bir Çerçeve. Sustainable Tourism Congress Proceedings Book, Gümüşhane Üniversitesi Yayınları.

Düşmezkalender, E., ve Metin, M. (2019). Alternatif Turizme Yönelik Bibliyometrik Bir Araştırma. Selçuk Üniversitesi Sosyal Bilimler Meslek Yüksekokulu Dergisi, 22(2), ss.813-824.

Elsasser, H., ve Bürki, R. (2002). Climate change as a threat to tourism in the Alps. Climate research, 20(3), ss.253-257.

Eurostat, (2019). European CommissionEurostat Statistics. https://ec.europa.eu/eurostat/web/products-eurostat-news/-/DDN-20191230-1 (Erişim Tarihi: 30.05.2020).

Falk, M. (2010). A dynamic panel data analysis of snow depth and winter tourism. Tourism Management, 31(6), ss.912-924.

Falk, M., ve Lin, X. (2018). Sensitivity of winter tourism to temperature increases over the last decades. Economic Modelling, 71, ss.174-183.

Figueroa-Domecq, Palomo, J., Flecha, M. D., Segovia-Perez, M.,ve Vico, A. (2017). Is the tourism and gender research area igniting: A bibliometric analysis. Revista Turismo \& Desenvolvimento, 27(28), ss.173-175.

Genç, R. (2019). Alternative Winter Tourism Activities: How Destinations Adapt to Other Activities than Skiing. Acta Economica Et Turistica, 5(1), ss.65-77.

Gomezelj, D. O. (2016). A systematic review of research on innovation in hospitality and tourism. International Journal of Contemporary Hospitality Management.

Gümüş, A., ve Yeksan, Ö. (2019). Ulusal Turizm Kongrelerinde Örgütsel Davranış Alanında Yapılan Bildirilerin Bibliyometrik Analizi. Yüzüncü Yıl Üniversitesi Sosyal Bilimler Enstitüsü Dergisi, Ek-1 Sayı, ss. :153-175

Güzeller, C. O. ve Çeliker, N. (2017). Geçmişten Günümüze Gastronomi Bilimi: Bibliyometrik BirAnaliz, Journal of Tourism and Gastronomy Studies, 5(2), ss. 88-102.

Hall, C. M. (2011). Publish and perish? Bibliometric analysis, journal ranking and the assessment of research quality in tourism. Tourism Management, 32(1), ss.1627.

Hewer, M. J., ve Gough, W. A. (2018). Thirty years of assessing the impacts of climate change on outdoor recreation and tourism in Canada. Tourism Management Perspectives, 26, ss.179-192.

Işık, C., Küçükaltan, E. G., Çelebi, S. K., Çalkın, Ö., Enser, İ., ve Çelik, A. (2019). Turizm ve girişimcilik alanında yapılmış çalışmaların bibliyometrik analizi. Güncel Turizm Araştırmaları Dergisi, 3(1), ss.119-149.

İncekara, A. (1998). Doğu Anadolu'da Kış Turizmi ve GelişmeOlanakları. İstanbul Ticaret Odası Yayın No:1998-18, İstanbul.

Jiang, Y., Ritchie, B. W., ve Benckendorff, P. (2019). Bibliometric visualisation: An application in tourism crisis and disaster management research. Current Issues in Tourism, 22(16), ss.1925-1957.

Kılıç, B.,ve Kurnaz, A. (2010). Alternatif turizm ve ürün çeşitliliği oluşturmada ekolojik çiftlikler: Pastoral Vadi örneği. Işletme Araştırmaları Dergisi, 2(4), ss.39-56.

Klasz, W., Bacher, M., ve Ressl, M. (2017). Sustainable Winter-Tourism: the Project Snow-Cloud. AGATHÓN International Journal of Architecture, Art and Design, 2, ss.197-204.

Koenig, U., ve Abegg, B. (1997). Impacts of climate change on winter tourism in the Swiss Alps. Journal of Sustainable Tourism, 5(1), ss.46-58.

Köseoğlu, M. A., Sehitoglu, Y., ve Parnell, J. A. (2015). A bibliometric analysis of scholarly work in leading tourism and hospitality journals: the case of Turkey. Anatolia, 26(3), ss. 359-371. 
Köseoğlu, M. A., Rahimi, R., Okumus, F., ve Liu, J. (2016). Bibliometric studies in tourism. Annals of Tourism Research, 61, ss. 180-198.

Kurtz M. ve Bollen J (2010) Usage bibliometrics. Annual Review of Information Science and Technology, 44, ss. 1-64

Matzler, K., ve Siller, H. J. (2003). Linking travel motivations with perceptions of destinations: The case of youth travelers in Alpine summer and winter tourism. Tourism Review, 58(4), ss. 6-11.

Merriam, S. B., ve Tisdell, E. J. (2015). Qualitative research: A guide to design and implementation. John Wiley ve Sons.

Mursalov, M. (2009). Bir turistik ürün çeşitlendirmesi olarak kış turizmi ve kış turizmi açısından Azerbaycan'ın Guba Haçmaz turizm bölgesinin arz potansiyeli, Yayınlanmamış Yüksek Lisans Tezi, Dokuz Eylül Üniversitesi, Sosyal Bilimler Enstitüsü, İzmir.Nebioğlu, O. (2019). Turizm ve Yiyecek Tüketimi: Uluslararası Alanyazın Üzerine Bibliyometrik Bir Analiz. Seyahat ve Otel İşletmeciliği Dergisi, 16(1), ss.71-88.

Nebioğlu, O. ve Kalıpçı, M. B. (2020). Planlı Davranış Teorisi ve Turizm Üzerine YapılanUluslararası Yayınların Bibliyometrik Analizi, Türk Turizm Araştırmaları Dergisi, 4(1), ss.1-14.

Oktayer, N., Susam, N. ve Çak, M. (2007), Türkiye'de Turizm Ekonomisi,İstanbul Ticaret Odası, İstanbul.

Olcay, A., Karaçil, G., ve Sürme, M. (2018). Helal Turizm Alanının Bibliyometrik Profili. Igdir University Journal of Social Sciences, (15), ss. 389-408

Osareh, F. (1996). Bibliometrics, citation analysis and co-citation analysis: A review of literature I. Libri, 46(3), ss. 149-158.

Osmund, H. A., ve Sunday, J. (2010). Winter tourism product development in Rovaniemi for Lapland Safaris. Rovaniemi University of Applied Sciences, ss.171.

Özel, Ç. H., ve Kozak, N. (2012). Turizm pazarlaması alanının bibliyometrik profili (2000-2010) ve bir atıf analizi çalışması. Türk Kütüphaneciliği, 26(4), ss.715733.

Pickering, C. M., Castley, J. G., ve Burtt, M. (2010). Skiing less often in a warmer world: Attitudes of tourists to climate change in an Australian ski resort. Geographical Research, 48(2), ss.137-147.

Polat, E., Düzgün, E., ve Yeşiltaş, M. (2019). İklim Değişikliğinin Turizme Etkisini Belirlemeye Yönelik Hazırlanan Lisansüstü Tezlerin Bibliyometrik Profili. Gümüşhane Üniversitesi Sosyal Bilimler Enstitüsü Elektronik Dergisi, 10, ss.240249.

Pütz, M., Gallati, D., Kytzia, S., Elsasser, H., Lardelli, C., Teich, M., ve Rixen, C. (2011). Winter tourism, climate change, and snowmaking in the Swiss Alps: tourists' attitudes and regional economic impacts. Mountain Research and Development, 31(4), ss.357-363.

Río-Rama, M., Maldonado-Erazo, C., Durán-Sánchez, A., ve Álvarez-García, J. (2019). Mountain tourism research. A review. European Journal of Tourism Research, 22, ss.130-150.

Rodríguez-López, M. E., Alcántara-Pilar, J. M., Del Barrio-García, S., ve Muñoz-Leiva, F. (2019). A review of restaurant research in the last two decades: A bibliometric analysis. InternationalJournal of Hospitality Management,ss.1-10

Ruhanen, L., Weiler, B., Moyle, B. D., ve McLennan, C. L. J. (2015). Trends and patterns in sustainable tourism research: A 25-year bibliometric analysis. Journal of Sustainable Tourism, 23(4), ss.517-535.

Ryan, C. (2002). Equity, management, power sharing and sustainability issues of the 'new tourism'. Tourism management, 23(1), ss.17-26. 
Scott, D., Jones, B., Lemieux, C., McBoyle, G., Mills, B., Svenson, S., ve Wall, G. (2008a). Vulnerability Of Winter Recreation to Climate Change. Climate Change And Tourism-Assessment And Coping Strategies.

Scott, D., Dawson, J., ve Jones, B. (2008b). Climate change vulnerability of the US Northeast winter recreation-tourism sector. Mitigation and adaptation strategies for global change, 13(5-6), ss.577-596.

Smith, K. (1993). 'The influence of weather and climate on recreation and tourism', Weather 48(12), ss.398-403.

Soboll, A., ve Dingeldey, A. (2012). The future impact of climate change on Alpine winter tourism: a high-resolution simulation system in the German and Austrian Alps. Journal of Sustainable Tourism, 20(1), ss.101-120.

Somuncu, M. (2018). İklim Değişikliği Türkiye Turizmi için Bir Tehdit mi, Bir Fırsat mı. Tücaum 30. Yıl Uluslararası Coğrafya Sempozyumu, 30, 748-771.

Sünnetçioğlu, A., Yalçınkaya, P., Olcay, M., ve Mercan, Ş. O. (2017). Turizm alanında yazılmış olan gastronomiye ilişkin tezlerin bibliyometrik profili. Journal of Tourism and Gastronomy Studies, 5(2), ss.345-354.

Şenol, F. (2008). Turizm Coğrafyass. Ankara: Detay Yayıncılık. Takeda, Y., ve Kajikawa, Y. (2010). Tracking modularity in citation networks. Scientometrics, 83(3), ss.783-792.

Tayfun, A., Küçükergin, F. N., Aysen, E., Eren, A., ve Özekici, Y. K. (2016). Turizm alanında yazılan lisansüstü tezlere yönelik bibliyometrik bir analiz. Gazi Üniversitesi Turizm Fakültesi Dergisi, 1(1), ss.50-69.

Temizkan, P., Çiçek, D., ve Özdemir, C. (2015). Bibliometric profile of articles published on health tourism Sağlık turizmi konusunda yayınlanan makalelerin bibliyometrik profili. Journal of Human Sciences, 12(2), ss.394-415.

Thanuskodi, S. (2011). Bibliometric analysis of Indian journal of agricultural research. International Journal of Information Dissemination and Technology, 2(3), ss.170175.

Tervo, K. (2008). The operational and regional vulnerability of winter tourism to climate variability and change: The case of the Finnish nature-based tourism entrepreneurs. Scandinavian Journal of Hospitality and Tourism, 8(4), ss.317332.

Toksöz, D., ve Birdir, K. (2016). Turizm Alanyazında Kültürel Mirasla İlgili Çalışmaların Bibliyometrik Profili (2006-2015).V. Doğu Akdeniz Turizm Sempozyumu I. Uluslararası Doğu Akdeniz Turizm Sempozyumu bildiri kitabı içinde (ss.76-88). Kuzey Kıbris.

Tüik. (2019). Türkiye İstatistik Kurumu, Turizm Verileri, https://biruni.tuik.gov.tr/medas/?kn=74\&locale=tr (Erişim tarihi: 30.05.2020).

Unbehaun, W., Pröbstl, U., ve Haider, W. (2008). Trends in winter sport tourism: challenges for the future. Tourism Review, 63(1), ss.36-47.

Van der Merwe, P., ve Saayman, M. (2008). Travel motivations of tourists visiting Kruger National Park. Koedoe, 50(1), ss.154-159.

van Raan, A. F. (2005). For your citations only? Hot topics in bibliometric analysis. Measurement: interdisciplinary research and perspectives, 3(1), ss.50-62.

Vogel, R., ve Güttel, W. H. (2013). The dynamic capability view in strategic management: A bibliometric review. International Journal of Management Reviews, 15(4), ss.426-446.

Yang, J., ve Wan, C. (2010). Progress in research on the impacts of global climate change on winter ski tourism. Advances in climate change research, 1(2), ss.5562.

Yeksan, Ö., ve Akbaba, A. (2019). Sürdürülebilir Turizm Makalelerinin Bibliyometrik Analizi. Güncel Turizm Araştırmaları Dergisi, 3(2), ss.220-231. 
Yenice, Z., \& Ercoşkun, Ö. Y. Türkiye'de Kış Turizmi Merkezlerinin İklim Değişikliğine Dirençliliğinin Değerlendirilmesi, Bolu Köroğlu Dağı ve Erzurum Palandöken Örnekleri. Resilience, 3(2), 269-285.

Yılmaz, G. Ö., ve Gürol, N. K. (2012). Balıkesir ilinin kırsal turizm potansiyelinin değerlendirilmesi. Karamanoğlu Mehmetbey Üniversitesi Sosyal ve Ekonomik Araştırmalar Dergisi, 2012(2), ss.23-32.

Zan, B. U. (2012), Türkiye"de Bilim Dallarında Karşılaştırmalı Bibliyometrik Analiz Çalışması, Yayınlanmamış Yüksek Lisans Tezi, Ankara Üniversitesi, Sosyal Bilimler Enstitüsü, Ankara.

Zeydan, Ö., ve Sevim, B. (2008). İklim değişikliğinin kış turizmine etkileri. TMMOB Iklim Değişimi Sempozyumu Bildiriler Kitabı, ss. 159-174.

Zhang, L., Janssens, F., Liang, L., ve Glänzel, W. (2010). Journal cross-citation analysis for validation and improvement of journal-based subject classification in bibliometric research. Scientometrics, 82(3), ss. 687-706. 